\title{
The Disruptions of African Indigenous Culture Experienced During COVID-19 Pandemic in Zimbabwe.
}

\author{
Prince Dzingirayi $^{{ }^{*}}$, Tendeukai Isaac Chinooneka ${ }^{2}$, Pauline Chitiga ${ }^{3}$, Blessing Mathabire ${ }^{4}$ \\ ${ }^{1}$ Women's University in Africa__ Department of Psychology Lecturer \\ ${ }^{2}$ Great Zimbabwe State University- Department of Educational Foundation Senior Lecturer \\ ${ }^{3}$ Ministry of Education-Manicaland Province, Mutare, Zimbabwe \\ ${ }^{4}$ Development and Policy Expert Director-Zimbabwe
}

*Corresponding Author: Prince Dzingirayi, Women's University in Africa _ Department of Psychology Lecturer, Zimbabwe

\begin{abstract}
COVID-19 pandemic is a healthy crisis which has painfully demonstrated cultural mayhem in the world over. The pandemic has created a profound shock, with different implications and complications to human life. Humanity has been turned upside down with direct unprecedented impact to traditional cultural practices such as socialisation, work, learning, bereavement, traditional remedies and different cultural ceremonies which cement the spirit of Ubuntu. COVID-19 has taken a leading role in paralysing and endanger the livelihoods of African people in different communities. The traditional African worldview of good health emphasises the interrelationship between human beings (the living) and the living-dead (ancestors). Traditional culture provides its members with behavioral pictures and it offers models of how people should or might feel and act in response to different pandemics.It is in this auspices that the paper focused on the African traditional crisis which emanate as a result of restrictive measures of curbing the spread of coronavirus in Zimbabwe. The study used the Transformative Paradigm (TP) and Critical Emancipatory Research (CER) as the beacon of the research. This research design enables the researcher and the researched to jointly get into the problem and collaboratively find solutions by interrogating the existing social and cultural vacuum. Data was gathered from the community elders who are custodians of culture. Data was collected through social media platforms of WhatsApp and Facebook and was analysed using response scripts. A convenient and opportunistic sampling technique was used in the study. The acclaim of pandemics has been experienced before and different cultural reactions are known. The research findings revealed that COVID-19 has genuinely affected cultural practices of bereavement handling, social interaction, learning, illness, life and death as well as destabilisation of cultural norms and values. As part of the recommendations of this study there is need to make use of traditional remedies so as not to disrupt important cultural practices.
\end{abstract}

Key Words: COVID-19, Indigenous African culture, disruption, Ubuntu

\section{INTRODUCTION}

The global COVID-19 pandemic has painfully demonstrated and recorded as the most devastating crisis which has hit humanity. There is much to be learnt from this pandemic and to be done in response, now and into the future at global, community and as well as at an individual scale. COVID19 is a systematic health crisis with deadly implications to livelihoods. The crisis needs to rewire human cognition since the future is hard to predict. The COVID-19 pandemic has threatened and disrupted the cultural systems of different communities across the globe. The world has been turned upside down due to the genesis of the so called COVID-19. Afrocentricpractices such as interaction, healing, burials, communication, work, learning and how to travel have been greatly affected. The researchers are busy trying to come up with solutions of how to adapt to the new normal of the pandemic, how to commute, travel without transmitting or contracting infection and, how to support those most affected by the crisis. The most notable gap which is being shunned by researchers is how the pandemic had ruined the Afrocentric culture in Zimbabwe. The World Health Organisation (WHO) COVID-19 regulations were imposed ignoring different traditional cultural beliefs in most 
communities. The COVID-19 pandemic has unleashed a human development crisis precipitated by superimposed tensions between people and culture.

\subsection{Background of the Study}

COVID-19 pandemic has brought geopolitical and psychosocial-economic challenges which has led to multi-dimensional issues. A new normal has been created by the COVID-19 pandemic. The COVID-19 pandemic had caused acute and existential disruption to African indigenous culture, humanity and livelihood in different communities. These radical changes created a need to react, and to be prepared for the worst.The coming of next horizons of the post-COVID-19 is centred on creating survival capacity of realising the need for a better tomorrow (Buheji and Ahmed, 2019). The pandemic has created a new normal of reaction supported by reflection caused by the sudden life changes (Buheji and Sisk, 2020; Levenson, 2020; OECD, 2019).

WHO (2020a) confirms that the novel coronavirus is a contractible virus through social intimacy and it can attacks the respiratory system with various scientifically proven symptoms like sneezing, fever and cough. The unprecedented spread and acceleration of the COVID-19 wave in the world, has caused most state government, including Zimbabwe to stipulate measures such as social distancing, shutting down the country as a way to curtail the spread of the coronavirus as propounded by the World Health Organisation (WHO, 2020a).

According to Buheji \& Buheji, (2020) the pandemic has caused cultural issues of human life, what we believe in, how we think, how we visualise our role in life, our next generation essentials, how we would react to a coming life crisis. The pandemic brought challenges and opportunities that are engulfed with many problems. There are many untapped problems that still need to be tackled, which could address the rising needs of humanity due to the pandemic. The solutions could form a central part of the early responses to the pandemic and manage the new environment created (Marshall et al, 2008). Guided by the historical background, whenever there is a deficiency the super powers would take advantage to derail the culture of weaker states. This was supported by Biko (2006) who argues that colonization by super powers have throughout history, resulted in nothing more sinister than mere cultural or geographical fusion at worst, or language bastardisation at its best. It is true that history of weaker nations is shaped by bigger nations, but nowhere in the world today do we see whites exploiting whites on a scale even remotely similar to what is happening in African countries (Biko, 2006). In the spirit of Ubuntu, collective unity was employed for every person's survival (Mogobe, 2003). This entails that the introduction of the COVID-19 guidelines were imposed from top to bottom without considering the indigenous beliefs systems. The imposed regulations can be rated as a colonisation tactic. It seems the guidelines are rather individualistic than collective in nature and this has greatly attracted the researcher to make an inquiry on the impact of the cultural disruptions caused by the COVID-19 restrictive measures of curbing the spread of the pandemic.

In line with the emergence of COVID-19 pandemic there are critical African traditional aspects which were soiled down. These aspects are interrelated and they function in a synergistic Afrocentric fashion. For instance communication is a deeply religious belief which is rooted in human behaviors and structures of African society. According to Mkhize (2004) there is a ritual process of communication which is important in understanding the dynamics of a people's culture and religiosity. Therefore, religion is so permeating in every aspect of African community. This research was lured by how Afrocentric beliefs system were being handled during the peak of the deadly coronavirus. The guidelines of curbing the spread of the coronavirus were put in place by WHO based on the scientific enquiry. However, the traditional belief systems was suddenly crippled leading to vacuum of honouring traditional values.

\section{LITERATURE REVIEW}

\subsection{Conspiracy Theories of COVID-19}

COVID-19 has garnered a number of conspiracy perspectives on social media since its discovery. The pandemic and conspiracy narratives carry highly contextualized cultural and political assumptions and nuances (Jovančević \& Milićević, 2020). The conspiracy theories help us alleviate our fears and anxieties especially during disasters like the sudden emerging of the pandemic. According to Constantinou, Kagialis \& Karekla, (2021) COVID-19 was created for human population control. 
There are a number of multiple conspiracy theories some are coiled around the technological advancement of the 5G. However, the most consistent archetypal conspiratorial thinking (Denovan et al., 2020), explain COVID-19 as a clandestine plots, influenced by powerful actors, to achieve malevolent goals (Sibley et al, 2020). Prominent examples include claims that COVID-19 was engineered in a laboratory as abioweapon (Lewis, 2020), and that vaccination is a pretext to implant tracking microchips into populations (Huddleston, 2021, January 12). The genesis of coronavirus was in Chinese town of Wuhan where an international laboratory for studying communicable diseases is found. This has raised some suspicions as the deadly virus is defined as a germ warfare testing of mass depopulation event. According to Freeman et al, (2020) the prolonged shock of quarantines, lockdowns, and social distancing accompanied an evolving information landscape from the international stakeholders charged with managing the disease has enveloped in conspiracy theory of popular distrust. The pattern of the waves of the pandemic and the incentivising of States by WHO on adhering to COVID-19 regulations is suspicious hence is in support of the secret behind coronavirus. In America research indicates that $62 \%$ believed that the media had greatly used to exaggerate the risks of the pandemic (Mitchell and Oliphant, 2020; Romano 2020).

\subsection{Conceptions of Ubuntu}

Traditionally, African societies tend to be cohesive and productive, working together as one family in their social grouping. Ubuntu is a way of life and the living of the people within their togetherness for the purpose of oneness, where everyone is important and treated equally, regardless of their differences. This was conceptualised by Omodan \&Dube (2020) as an Africanised way of living. Afrocentricism, is synonymous with selfless services, caring for others, respecting and protecting others from dangers (Mbiti, 1969). In the same vein, Ubuntu philosophy preaches humanness, humanity, and morality for social relatedness and a person's well-being, leading to a better quality of life and a better community (Jolley, 2011). The above show that Ubuntu is a way of life that brings common people together for their development. Tutu (1999) supports that Ubuntu philosophy gluespeople with their common goals in a jointly and non-discriminatory manner. According to Sodi, (2016) Ubuntu is an apostle of dignity, empathy, oneness and generosity. This means the philosophy of Ubuntu could produce collaboration, corporation, trust, and respect between members of the community. Therefore, African Ubuntu collectivism cultivates a team spirit towards work

The restrictive measures of COVID-19 has created a cultural vacuum which could be difficult to fill. The collective interrelatedness and love has been ruined within the Afrocentric culture. Ubuntu helps to pinpoint the psycho-social deficiency caused by the effect of COVID-19 restrictive measures to be accommodative and balance African cultural way of life. This is confirmed by the argument of Hoffmann and Metz (2017) that Ubuntuism plays a pivotal role in gingering the capability of people towards themselves. The Ubuntu spirit enhances love and compassion for individuals affected and infected by the pandemic. The Afrocentricculture cement the spirit of working together without hitches and can ease any psychological stress that might affect the community during the lockdown and or during the peak of the pandemic. The humanness in Ubuntu philosophy enables people to propose integrated ideas and foresight towards nurturing and developing ways to increase the potentials of the system (Sarpong, Bi \& Amankwah-Amoah, 2016) to respond to community needs. The implementation of WHO regulations posed cultural impediment for rendering cultural related solutions to curb the spread of the COVID-19.

\subsection{The African indigenous values}

The health and wellness of African individuals are reliant on the integration of mind, body, and spirit. According to Mbiti (1969), although unseen, the supernatural world exerts a powerful influence over the natural or visible world and also is responsible for all that goes on in the physical world. This means indigenous African spirituality involves deeper human values, attitudes, beliefs and practices, based on various African worldviews. For instance most Africans value the concept of spirituality and the equilibrium relationship between the dead and the living. The traditional healing system is however closely bound to the culture of people. Death is not seen as the end of life but rather as a way of moving on to join the company of the departed in a state of collective immortality. In the Afrocentric view when a person dies he lives the spiritual world and assumes supernatural power, which enables him to influence and protect the living or punish them for disrespecting the dead. In the traditional family, harmony was rated as the most important value for all family members (Shizha \& 
Charema, 2008). One of the essential element of harmonising the African relations is by respecting the authority and elders. The respect given to the elders has its practical effect in the maintenance of custom and tradition.

According to Mbiti (1969) religion shapes community worldview leading to active social participation. In this regards the African traditional religious belief entails that human beings do not live in this world alone. There is a co-existence between humans and nature. There are also spiritual beings that are more powerful than humankind and this opens up the African to the divine and to seeking affinity with these spiritual powers. Religious belief is thus diffused in all spheres of life filling them with meaning and significance (Ejizu, 1996). Traditional beliefs can best be observed during social activities such as family gathering, funeral, traditional ceremonies and trading.

African spirituality is traditional, not because it is a fossil, static and incapable of adaptation to new situation and changes, but because it is a spirituality that originated from the people's environment (Nobles, Baloyi \& Sodi, 2016). It is a culture which is learned and imitated by all belonging to various specific spiritualties. Consequently, an African spirituality is one where an African is inserted into his/her traditional beliefs and practices through a well-defined system of rites of passage which make up a culture. Each person is born into it, lives it, practices it and is proud to make it his/her own Africans exercise their spirituality in all of their daily activities. However, the emergence of the COVID-19 pandemic has disrupted the Afrocentric values as the WHO guidelines did not accommodate cultural believe systems.

\subsection{African Traditional Ritual Ceremonies}

Rituals ceremonies are of significance value within the African worldviews in wellness and illnesses. According to Mpofu (2006), ritual enactment is one of the approaches used in healing, burial, rainingmaking, casting away malevolent spirits among others. African worldviews maintain that traditional elders or individuals with a special calling preside over traditional rituals. Ritual ceremonies serves to connect fundamental abstract principles of a culture (Turner, 1967). For example healing in the African worldviews does not just take place in any place. There are designated places for healing where the rituals are performed such as at shrines like scared mountains. African communities have a series of rituals that are related to the environment from cradle to grave. In line with the COVID-19 restrictive regulations stop individuals to travel from place to place hence disrupting the traditional beliefs system.

\subsection{Traditional African Healing System}

Restoration of health from an African perspective, lies within the social, cultural and historical contexts. Mpofu (2006) discusses that healing is knowledge and practices used in the diagnosis, prevention and elimination of physical, mental and social imbalance. The healing approaches of coronavirus also lies within the purview of the African cultural belief system. The Afrocentric approaches of healing different ailments are centred on supernatural power and natural world. The root cause of wellness or ill health from the African perspective is explained in metaphysical terms. The African worldviews emphasize holistic healing, that is, healing approaches that encompass spiritual, psychological and physical aspects of the illness (Mkhize, 2015).In African traditional healing ceremonies, the dynamics of human relationships is crucial for the healing. The African indigenous culture is interwoven with religious web which influences the notion of health and wholeness. Sickness of an individual in the African societyis viewed as sickness to the entire community.

\subsection{Research Objectives}

To explore the Afrocentric cultural crisis caused by the COVID-19 lockdown restrictive measures.

To come up with possible African solutions that could help to curb the spread of the COVID-19 challenges.

\section{Methodology}

\subsection{Research Paradigm and Design}


The study used the Transformative Paradigm (TP) as the beacon of the research. The TP is best commendable to present the people's quest for transformation through a collective approach. This paradigm addresses the issue of social justice towards transformation and involvement to change theexisting situation for better (Mertens, 2007). Dube (2016) and Omodan (2020a) acumen that TP tend to change the existing status quo of the participants for better. To ensure that the current traditional disruptions are ameliorated, the study adopted Critical Emancipatory Research (CER) as a research design. This research design enables the researcher and the researched to jointly get into the problem andcollaboratively find solutions by interrogating the existing social and cultural vacuum. This design isrelevant to guide the study because it aims to reform, transform, emancipate and free the people from conspiracy, scientific and ideological enslavement (Dube and Hlalele, 2018; Omodan \& Dube, 2020). The design also enables the researcher to engage in a transformative and participatory process of inquiry on cultural challenges caused by COVID-19 and come up with possible African solutions to stop the spread of coronavirus.

\subsection{Participants and Selection of Participants}

The research participants are the community elders and traditional leaders who are custodians of traditional culture in rural areas of Zimbabwe. A convenient and opportunistic sampling technique was used in the study. This technique is relevant because of the current lockdown situation in Zimbabwe. The opportunistic selection method is used when dealing withsocial issues, where the expected participants are not easy to access (Brady, 2019). That is, the groups areeither regimented, vulnerable; possess hidden characteristics, among others (Mason, 2001). Because of the current national lockdown, the participants are hard-to-find and are considered to be regimented. A semistructured interview was used to gather data from the participants using social media platforms such as WhatsApp, emails, Facebook and phone calls because there was a total lockdown in the country at the time of the study.

\subsection{Data Analysis and Ethical Consideration}

The study used Socio-thematic Analysis to interpret the data collected through interviews. The Sociothematic Analysis is a way of generating data by integrating the sociality of the participants in themes (Omodan, 2019). The data was coded in to themes and each theme was subjected to conversational interpretation in a way to understand the sociality of the participants since the problem under study is centred on Ubuntu kind of social space. Ethical issues of protection from harm, confidentiality, seeking permission from the gatekeepers and competences were honoured during the study.

\section{RESUltS AND DiscusSiON}

The study had fished out the following themes from the responses of the participants:

- Communication and social distance

- Healing and sickness

- Burial practices and respecting the dead

- Common traditional ceremonies

\subsection{Communication and Social Distance}

The participants had air out that African indigenous people's relationship is cemented by culture. Culture entails the communication style, dressing, language and beliefs. All the participants were concerned by the restrictive measures that were put in place during the COVID-19 restrictive measures. Indigenous way of communication signifies oneness. Communication is a way of gathering and learning in the Afrocentric worldview. Therefore during the peak of the coronavirus communication between individuals were paralysed. One responded states that African people had their way of life which is different from the Eurocentric. African can communicate with their ancestors at sacred places such as at Mabweadziva, Matopo, Domboshava and many more. At these places they will be communicating their grievances with their forefathers (ancestors). The ancestors plays a noble role of protecting the living or they can punish them if they disrespect them. These is in support withMbiti (1969) who argues that the supernatural world exerts a powerful influence over the natural or visible world and also is responsible for protection and all that goes on in the physical 
world. This means the genesis of the coronavirus was known and community members were being protected by their ancestors. Most participants agree that this was proved by the number of casualties of the deadly coronavirus and the number of recoveries as compared to infected and affectedpeople in the western countries. The spirit plays a centre stage in making sure that indigenous people were under protection. Therefore the remedy of curbing the spread of the coronavirus cannot ignore the contribution of the spirituality.In Africa, the spiritual belief system is a noble determinant of choice of treatment.

Social distance is another key area that had been raised by the respondents. Most participants shared that social distance is the promotion of the Eurocentric culture. The Eurocentric worldview is individualistic as compared to the Afrocentric world view which is centred to collectivism. Culture is collective, unique and dynamic and is transmitted from one generation to the other through socialization. The Eurocentric culture is individualistic in which behaviour is determined by personal goals while in collectivist culturesbehaviouris determined by community goals. Self-alienation produces unnatural rejection of indigenous life practices, unnatural imitation of alien invaders and a lack of consciousness. An individual is defined by his/her environment. This was in support of Tutu, 2017; Mkhize, 2016; Sodi,2006"I am because we are". This was also supported by Mkhize (2004) with the context that humans are made persons by other persons. This means African worldview rejects the notion of the Western individualistic picture of human beings thatclamour on the idea of humans as self-contained units, in total control and in-charge of their own destiny. Other participants had indicated that social distance had stopped the behaviour of hand shake. Handshake is a way of communication which has different meanings. The behaviour of handshake resembles unity, respect, harmony, love and care which constitutes the component of Ubuntu in the Afrocentric view. The communication of handshake can be done at funeral as a way of consoling the bereaved family. In the African indigenous culture the death or illness of a community member mean the community is not well. Therefore collective behaviour is a noble principle which can be transcended through hand shaking. Most participants raised conspiracy of the pandemic. This entails that whatever African do should be guided by their culture of Ubuntu not to be guided by WHO. Such pandemics used to be there and our forefathers had best ways of controlling. The concept of quarantine was used in the African way which they call "kumativi" and has been done to individuals which communicable diseases such as leprosy, measles and many more. The quarantine practice was used to be done coiled around Afrocentric values. One participant indicates that ignoring indigenous African practices is a deliberate move by the west countries.

\subsection{Healing and Sickness}

Africans had different meanings to the causes of sickness and the remedy can be directed through spirituality. As Africans we had our own way of healing different ailments depending with the cause. In the African worldview healing can be done using herbs, casting out evil spirits, sorcery, ritual ceremonies, use of animals and bones. This resonates with the work of Machinga (2011) African people believe that illness and death cannot just happen without a spiritual force behind it. Africans believe ill-health to have material, moral, supernatural and pre-natural causes which can be determined by both physical observation and divination (Edward, 2011). Therefore the COVID-19 restrictive guidelines compromised the way how Africans can respond to the outbreak of diseases. Masaka \& Chingombe (2009), any mishap has a spiritual connection which needs to be known so as to give correct solutions. This entails that African problem needs African solutions. Most participants support the notion that locally available resources can be the best solution to the coronavirus. What needs to be done is to make consultation with the ancestors so that they can be given the solution. Therefore, the restrictive measures failed to respect the role of indigenous knowledge in finding the remedy of the deadly virus. However, during the peak of the disease some individuals turned to resort to the use of traditional herbs such as the fever bush tree (zumbani). In the Afrocentric view, the best way of healing is to centre on African belief system since religion is seen as a key to daily operations among the indigenous African people. Healing among the indigenous African we seek divine interventions from traditional healers, herbalist, and spirit mediums among others. Therefore during the peak of coronavirus it was so prudent to give room to infected person to seek divine support. There are so many causes of illness according to the indigenous African people which are witch craft, avenging spirits, sorcery, and divine punishment. 


\subsection{Burial Practices and Respecting the Dead}

The behaviour of Africans is motivated by what they believe, which is based on what they experience. A strong belief in supernatural powers is deeply rooted in the African culture. The participants point that the way how people died with coronavirus disrupt the African culture. In the African culture the dead body is respected and needs a respected send off. Death is part of life, it is a gateway to eternity, and it is a gateway to life in the hereafter. During burial people usually practice hand shaking as a way of comforting, and showing oneness. In the African culture if we fail to respect the dead person we will be creating problems to the next generation. If the dead person is not happy he/she would fight back by causing misfortunes such as sickness or death. This was supported by Waldron (2010) who points that the deceased individuals transform into invisible ancestral spirits and involve themselves in all aspects of life, including assisting individuals in obtaining good fortune, assisting with interpersonal relationships, and promoting good health and preventing illness. The spirit of ancestor have a lot of power and are both feared and respected. In the African indigenous beliefs when such pandemic like COVID-19threatens the livelihoods community elders appeal to the ancestors for advice. There are so many activities that were disrupted by the handling or burial of a person died of coronavirus such sharing his/her property as a way respecting the dead person. However, during the peak of the COVID-19 limited members of the community were allowed to attend funerals which the violation of African norms and Ubuntu values. After the death of a person especially an adult, the process of kurovaguva (bring home ceremony), is done to bring back the deceased's spirit to protect the family. All these were a thing of the past as it was seen as ways of spreading the coronavirus.

\subsection{Common Traditional Ceremonies}

Traditional knowledge contains some deep purity of values which is somehow gradually being eroded and lost due to foreign induced beliefs. The COVID-19 restrictive measures acted as a way of eroding the indigenous traditional culture. In the life of an indigenous African there are so many ceremonies that are being done at family level, community and national levels which glues the community together. One participant had alluded that there so many traditional ceremonies which were put on hold as a result of the coronavirus hence disrupting the indigenous African culture. This study has picked that the sense of sharing and caring is the pillar within the African indigenous culture. Caring can best be shown to a sick member of the community. Sharing cultivates the spirit of togetherness and it can be noted during different cultural events such as at funeral, harvesting ceremonies, celebration of cultural festivals by the community as a whole among others. Therefore, during the restrictive measures of COVID-19 the spirit of not working together was being cultivated. For instance collective gathering such as harvesting ceremonies (nhimbe) were suspended which then compromise the Africanism.

Ceremonies such as the "the rain- making, marriage ceremonies, kurova guva, (bringing back home ceremony), healing ceremony, and other ritual ceremonies which defines the African spirituality were disrupted by the COVID-19 guidelines. Therefore COVID-19 had significantly affected the way of life among the indigenous people. In conducting the rituals ceremonies, families can go beyond the physical into to the social and spiritual aspects of reality.

\section{CONCLUSiON}

COVID-19 has changed every aspect of an indigenous African culture. The study had concluded that the COVID-19 restrictive measures had caused more harm than good to the traditional culture. Communication, healing, burial, ritual ceremonies and other African activities which defines the concept of Ubuntu had been paralysed by the emergence of the COVID-19 pandemic. The research found that the restrictive measures are anti-Afrocentric since the WHO COVID-19 guidelines are laced around individualistic behaviours and suspending the collective culture of the indigenous African quarters. The pandemic has brought religious and social disintegration since the traditional religious and cultural threads that glues society together are indefinitely suspended. This in actual fact means COVID-19 had caused cultural fading within the African community. Future research should focus on the possible ways to addressing cultural injustice faced during the peak of the pandemic. The study recommends to have a collaborative measures of curbing the spread of the pandemic. The African problems should be solved using the African way. For this to happen there is need to 
empower the communities and respect indigenous traditional culture. The study recommends to incorporate indigenous African traditional remedies in the hospitals during the outbreak of such pandemics.

\section{REFERENCES}

[1] Asante, M. \& Asante, K. (1985). African culture. Westport: Greenwood Press.

[2] Bennett, T.W., \& Patrick, J. (2011). Ubuntu, the ethics of traditional religion. In T.W Bennett (ed) Traditional African religions in South African Law (pp 223-242). CapeTown: UCT Press.

[3] Biko, S. (2006).I write what I like: A selection of his writing. Johannesburg: Picador.

[4] Constantinou, M., Kagialis, A., and Karekla, A. (2021). COVID-19 Scientific Facts Vs. Conspiracy Theories: 0 - 1: Science Fails to Convince Even Highly Educated Individuals, DOI: https://doi.org/10. 21203/rs.3.rs-33972/v1

[5] Denovan, A., Dagnall, N., Drinkwater, K., Parker, A., and Neave, N. (2020).Conspiracist beliefs, intuitive thinking, and schizotypal facets: a furtherevaluation. Appl. Cogn. Psychol. 34, 1394-1405. doi: $10.1002 /$ acp. 3716

[6] Edwards, R. (2011). Herbs and healers of the north: Medicine, practices and philosophies inIslamic and traditional healing in Northern Ghana. Independent Study Project (ISP) Collection, 1250. Retrieved from http://digitalcollections.sit.edu/isp_collection/1250

[7] Ejizu, C.I. (1996). "Emergent Key Issues in the Study of African Traditional Religion," http://www.afric aworld.net/afrel/ejizu.htm

[8] Freeman,D., F. Waite, L. Rosebrock, A. Petit, C. Causier, A. East, L. Jenner, A.-L. Teale, L. Carr, S.Mulhall, E. Bold, and S. Lambe. 2020."Coronavirus Conspiracy Beliefs, Mistrust, and Compliance with Government Guidelines in England." PsychologicalMedicine: 1-13, https://doi.org/10.1017/S0033 291720001890.

[9] Gyekye, K. (1996). African Cultural Values: An Introduction Accra: Sankofa Publishing Company

[10] Huddleston, T. (2021). Here's What Bill Gates Has to Say About ThoseCovid-19 Vaccine Conspiracy Theories He's Pegged to. CNBC. Availableonline at: https://www.cnbc.com/2020/06/05/bill-gatesresponds-to-bizarrecovid-19-vaccine-conspiracy-theories.html

[11] Jovan`cevi'c, A.; Mili'cevi'c, N.(2020). Optimism-pessimism, conspiracy theories and general trust as factorscontributing to COVID-19 related behavior-A cross-cultural study. Pers. Individ. Dif. 167, 110216

[12] Lewis, T. (2020). Nine COVID-19 Myths that Just Won't Go Away. ScientificAmerican. Available online at: https://www.scientificamerican.com/article/nine-covid-19-myths-that-just-wont-go-away/

[13] Machinga, M. (2011). Religion, Health, and Healing in the Traditional Shona Culture of Zimbabwe, Spring; Emory University

[14] Mbiti, J. S. (1969). African religions and philosophy (2nd ed.). London: Heinemann.

[15] Mkhize, N. (2004). Socio-cultural approaches to psychology: Dialogism and African conceptions of the self. In D. Hook, N. Mkhize, P. Kiguwa, \& A. Collins (Eds.), Critical psychology （pp. 53-83). Cape Town: UCT Press.

[16] Mkhize, N. (2013). Psychology: An African perspective. In K Ratele, N Duncan, D Hook, N Mkhize, P Kiguwa, \& A Collings. Self, community \& psychology (pp. 4-1-4-29). Claremont: Juta and Company Ltd

[17] Mitchell, S. S. (2019). Population control, deadly vaccines, and mutant mosquitoes:the construction and circulation of Zika virus conspiracy theories online. Can.J. Commun. 44, 211-237. doi: 10.22230/cjc. 2019v44n2a3329

[18] Mitchell, A., and J. B.Oliphant. (2020). "Americans Immersed in COVID-19News; Most Think Media are Doing Fairly Well Covering It." PewResearch Center. https://www.journalism.org/2020/03/18/americansimmersed-in-covid-19-news-most-think-media-aredoing-fairly-well-covering-it/ (accessed January 7, 2021).

[19] Mogobe, R. (2003). The Philosophy of Ubuntu and Ubuntu as a Philosophy. The African Philosophy Reader $\left(2^{\text {nd }} E d.\right)$. London: Routledge. 
[20] Mpofu, E. (2006). Majority world health care traditions intersect indigenous and complementary and alternative medicine. International Journal of Disability, Development and Education, 53: 375-380.

[21] Nobles, W.W., Baloyi, L. \& Sodi, T. (2016). Pan African Humanness and Sakhu Djaer as Praxis for Indigenous Knowledge Systems. Journal for the Study of the Arts and Humanities in Southern Africa: Alternation Special Edition 18 (2016) 1-11:ISSN 1023- 1757

[22] Nussbaum, B. (2003). African Culture and UBUNTU. Reflection of a South African in America. World Business Academy Journal, 17 (1):1-12

[23] Nwoye, A. (2006). A Narrative Approach to child and family Theraphy in Africa. Contemporary family Therapy Journal. 28(1):1-23.

[24] Omodan, B. I. (2020). Managing the Psycho-Social Vacuum of COVID-19 among Rural Learners through Ubuntu. DOI: https://doi.org/10.36941/jesr-2020-0125

[25] Romano, A.(2020). "Study: Nearly a Third of Americans Believe aConspiracy Theory about the Origins of the Coronavirus." Vox.https://www.vox.com/covid-19-coronavirus-us-responsetrump/2020/4/12/2121764 6/pew-study-coronavirus-originsconspiracy-theory-media.

[26] Shizha, E. \& Charema, J. (2008).Counseling Indigenous Shona People in Zimbabwe: Traditional Practices Versus Western Eurocentric Perspectives .Journal of Psychology and Counseling, 4(5):59-67.

[27] Sibley, C. G., Greaves, L.M., Satherley, N.,Wilson,M. S., Overall, N. C., Lee, C. H.,et al. (2020). Effects of the COVID-19 pandemic and nationwide lockdown ontrust, attitudes toward government, and wellbeing. Am. Psychol. 75, 618-630.doi: 10.1037/amp0000662

[28] Sodi, T. (2009). Indigenous healers' diagnostic and treatment methods for illnesses a dysfunctions. Indilinga: African Journal of Indigenous Knowledge Systems, 8(1), 60-73. doi:10.4314/indilinga. v8i1.48243

[29] Turaki, Y. (1999). Christianity and African gods: A Method in Theology, Nairobi: IBS-Nig. Press.

[30] World Health Organization. (2020a). Coronavirus disease 2019 (COVID-19) situation report (Report No. 87). https://www.who.int/docs/default-source/coronaviruse/situation-reports/20200416-sitrep-87-covid19.pdf? sfvrsn=9523115a_2

[31] World Health Organization. (2020b). Coronavirus disease (COVID-19) advice for the public. https://www. who.int/emergencies/diseases/novel-coronavirus-2019/advice-for-public

\section{AUTHORS' BIOGRAPHY}

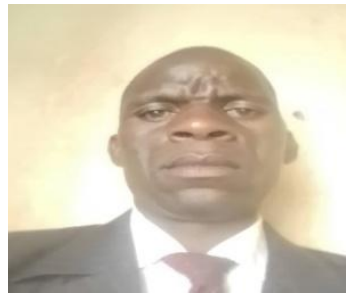

Prince Dzingirayi, is a PhD student at the University of KwaZulu-Natal and he is a Psychology lecturer at Women's University in Africa. He is a registered Psychologist in Zimbabwe. He holds several qualifications which include a Master in Community Psychology, Bachelor of Social Sciences Honours in Psychology and a Diploma in Education. He published more than a dozen of research papers with different journals. His research interests are centred on indigenous knowledge system (IKS), Community development, mental health issues, disability studies, Psychological interventions and assessment, and behavioural challenges.

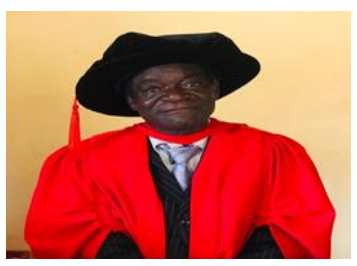

Tendeukai Isaac Chinooneka, is a Lecturer in the School of Educational Foundations at Great Zimbabwe University. He holds a PhD in Educational management from the University of KwaZulu-Natal. Dr Chinooneka had awards. Some of the notable awards are 'Zimbabwe liberation medal and the Zimbabwe independence medal'. He pursues research interests in Educational management, curriculum innovation, teacher education, transformative learning and indigenous knowledge systems. He has a broad record of research and he has over 7 publications in scholarly books and refereed journals. He has lectured in over $\mathbf{1 0}$ educational courses in different programmes. He is also the Provincial War veteran Chairperson. $\mathrm{He}$ has facilitated at many workshops locally and globally.

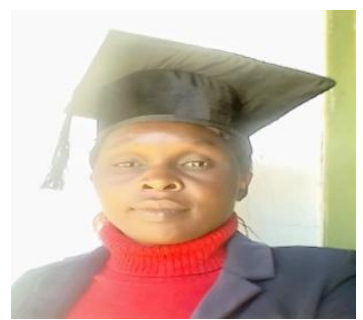

Pauline Chitiga, is an Early Childhood Development [ECD] teacher for 12 years. She holds a degree in Early Childhood Education at the University of Zimbabwe. She is a focused researcher and her research interests are centred on culture, anxiety in Early Childhood learners and vulnerability of women. She is pursuing a Masters in ECD. 
BlessingMathabire, is a development and foreign policy expert on Zimbabwe. He holds several qualifications which include a Master of Science in International Relations (MIR), 2016 from the University Of Zimbabwe (UZ). He also holds a Bachelor of Science Special Honours in Politics and Administration (SPA), 2014 (UZ). He pursued a Bachelor of Arts Degree (History and Philosophy), 2013 (UZ). He has a Diploma in Public Relations from the Zimbabwe Institute of Public Relations (ZIPR), 2014. He also holds a Certificate in Journalism and Communication (2013) from the Zimbabwe International College. In addition he holds a United Nations Certificate of Participation in Climate Change International Legal Regime, 2020. He has a pending Certificate in Project Management from the UZ. His research interests are in international relations, climate change, security and conflict studies, public sector development and project management.

Citation: Prince Dzingirayi, et.al. " The Disruptions of African Indigenous Culture Experienced During COVID-19 Pandemic in Zimbabwe." International Journal of Humanities Social Sciences and Education (IJHSSE), vol 8, no. 6, 2021, pp. 10-19. doi: https://doi.org/10.20431/2349-0381.0806003.

Copyright: (c) 2021 Authors. This is an open-access article distributed under the terms of the Creative Commons Attribution License, which permits unrestricted use, distribution, and reproduction in any medium, provided the original author and source are credited. 